\title{
Exploration of the Effect and Orientation of Psychological Factors in Non-commissioned Officer Education
}

\author{
Xinwei Gao, Dongqiu Xing, Jingna Cui, Lihua Qi, Wenbin Zheng, Kun Yang, \\ Feiran Chen
}

\author{
Test Training Base of Information and Communication School, National University of Defense \\ Technology, Xi'an 710106, China
}

\begin{abstract}
The psychological factors have become unavoidable problems in the learning and growth process of Non-commissioned officers due to the pressure learning and training, or the impact of life experiences, negative psychology affects the learning effect of the students, and even causes the students to deviate from the normal life track, if we carefully study the different effects of negative psychology and positive psychology, intervene in combination with positive psychological orientation in the learning process, explore the development of implementation means, give full play to the great advantages of psychology in the teaching process, and it will make the students' learning effect and psychological quality training have a complementary effect.
\end{abstract}

Keywords: Psychological Factors; Negative Psychology; Positive Psychology.

\section{Introduction}

As a higher education military school teacher in front-line teaching, I always hope that the students are eager to learn, to teach the knowledge which I have known, but I can always find that some students are absent-minded and even hate learning, there is a very important reason: the psychological factors of the students are not motivated, even having a counterproductive effect. As a comprehensive psychological quality, psychological quality not only determines the individual psychological level, but also restricts the formation and development of other abilities and qualities.

The theory of knowledge uselessness is deeply entrenched in the minds of some Noncommissioned officers, although they insist on studying and doing the test under the urging of the teachers, they do not pay attention to accumulation, do something as a mere formality, and pretend to work hard, even if they fail the exam, they still don't care. The fundamental reason is that they do not really feel the power of knowledge, the deep impact of knowledge on work and life; they do not really feel the danger of lack of knowledge to their future, so they turn a deaf ear to all kinds of preaching.

These negative psychologies are like time bombs hidden in the minds of the students, normally, no harm can be seen, and however, once there are induced factors or accumulated to a certain extent, this bomb will cause the consequences to erupt extremely seriously, even if they regret it again, it is difficult to recoup their losses.

Moreover, we find that people with positive energy will show a persistent and positive attitude in difficult situations, can consciously seek breakthroughs in the face of setbacks, and are persevering, this mentality is often the key to victory, in addition, the healthy psychology can make people think positively, and treat good and bad places correctly, this kind of psychology can be called positive psychology.

Negative psychology and positive psychology can lead people and things to different results in the same situation, if we study the effects and harms of negative psychology on students' behaviors, study the motivation and promotion of positive psychology on students' learning, try to run through the psychological guidance in the teaching process, flexibly use scientific and reasonable methods, and even turn the negative psychology to the positive psychology, which will bring good improvements to the learning effect of the students! 


\section{Harmful Effects of Negative Psychology}

College students are in a special period of life growth, almost all behaviors are directly or indirectly related to the psychological state of the college level, their learning situation and health state are deeply affected by psychological factors, however, at this stage, the strength allocation of psychological guidance institutions for college students is far from reaching the ideal level, "the psychological crisis of college students is still an extremely realistic problem, and it is also a very serious social problem, it includes the outbreak of psychological problems of college students, the long-term accumulation of emotions, the stress response to emergencies, etc."[1], since psychological pressure is not controlled and relieved in time and effectively, the negative psychology produced often leads to bad results.

Non-commissioned officers of higher education have heavy studies, strict management, and also need to pay attention to training, they are prone to some psychological problems under greater pressure, we often find such situations, some students usually perform well, can actively answer questions, can both sing and dance, but they show timidity and self-doubt as soon as they take an exam, this situation is similar to the "Jansen effect" in psychology, people call the phenomenon when performing well in normal times but fail in official games due to the lack of proper psychological quality as the Jensen effect, this kind of mental state lacking identity requires timely encouragement and practice to get out of the shadows. Once negative psychology occurs, the physical and mental health of the students will deviate from the normal track, and they will be depressed or excited in emotion, this instability can also easily lead to accidents, for example, infatuated with the Internet, gambling, drowsiness, mental illness, suicide, crimes, violations of regulations and disciplines, etc.

On the other hand, the negative psychology makes the Non-commissioned officer students produce disgusting or indifferent attitude towards learning, they are indifferent to the learning situation and purpose, which greatly affects the completion of the students' studies, and even has a deep and irreversible impact on the life path. The specific manifestations in learning are: absent-minded in class, turn a deaf ear to teachers' preaching, indifferent to grade, acceptance of the learning process becomes a mere formality, more and more obscure about the learning effect and purpose, repeat grade, drop out, etc. Many students have certain psychological obstacles in their studies or life for a while, henceforth collapse after one setback, and falter.

Dialectical materialist philosophy has such a thesis: "matter determines consciousness, and consciousness has a counter-effect to matter", and psychology corresponds to consciousness, and behavior corresponds to matter. On the one hand, it means that while seeking to improve the psychological orientation, it is necessary to dig out the causes of negative psychology, sort out, trace the source, and solve the source problem. On the other hand, psychology has an active role for behavior, negative psychology not only reflects the shortcomings of previous behaviors, but also affects the next behavior, therefore; we need to improve negative psychology, promote mental health, and improve and motivate the next behavior to go on the right track.

At present, most of the mental health education work of college students in military academies and local colleges is in the negative treatment orientation of preventing and treating mental illness, this positioning is weighted in the medical treatment of mental disorder, it does not intervene at the source and process stage of negative psychology, makes college mental health education present the characteristics of formalization, medicalization, and localization. Moreover, it also makes college students produce the willingness to avoid psychological problems and lose self-test and adjustment. Psychological problem has become a sharp knife that endangers the physical and mental safety of college students, in particular, under strict discipline requirements, military school students are under greater pressure and need to master methods to relieve psychological pressure, schools should also take advantage of the college good campus environment, adopt the pressure reduction method that students are willing to accept, take active intervention and guidance during the learning process, help students actively adjust their mental state, shape their tough character and good mentality, in dealing with negative psychological problems, let the students master the correct action guide, and get positive psychological persuasion and guidance. 


\section{Positive Effects of Positive Psychology}

"University is an important development stage of life, judging from the external environment, college students need face greater changes in the living environment and the increasing studies and life pressure; judging from the personal development, college students also need to build self-identity, and maintain the balance between maintaining personality and meeting social expectations"[2], the mental endurance and response in the face of pressure should be coordinated with the growth and development of college students, so that personal psychology and abilities can be fully developed, this is also a kind of ability that students in military schools urgently need to master in a typical military education environment.

The opposite of negative psychology is positive psychology, for example, the well-known "Rosenthal effect" of psychology, it announced and predicted the list of randomly selected students as the list of students who have outstanding development in the future, motivated the learning motivation of the students on the list, and achieved unexpected results, this kind of performance shows the important role of positive motivation, it motivates students to make progress in the form of psychological hints and guides them to make the right choice. Therefore, positive psychology is not only manifested in the persuasion of psychological problems, but also in the correct guidance of corresponding actions. When facing a difficult situation, what kind of response the individual adopts is crucial, everyone's response also has his own unique brand, when facing a stress situation, since the situation of stress or frustration is often changing, and this cause the response will also change accordingly [3]. According to the attitude that the individual adopts when facing pressure, the responses can be divided into positive response and negative response, negative response is when facing pressure, the individual only thinks about how to escape the pressure, and uses avoidance, fantasy, venting and other negative methods to avoid problems, active response is that the individual adopts positive strategies to face problems, for example, solves problems and seeks help to face and relieve pressure. Under pressure, if individual can take a positive response, not only can he avoid serious negative injuries, he can maintain normal cognition and behavior, but also may gain new growth and positive development. For example, when a student is hesitant to give up or continue, tell him the different results of the two choices in advance, actively encourage the student, and help find a way to solve the problem, this is a positive psychological intervention in combination with behavior, if this behavior like this is integrated into classroom teaching, effectively use psychological guidance, students will get out of confusion and happily accept knowledge and skills. On the one hand, the psychological problems of the students are alleviated and guided; on the other hand, the teaching effect is undoubtedly improved.

\section{Teaching Practice Should be Combined with Psychological Guidance}

Teachers should pay close attention to the mind state and acceptance condition of Noncommissioned officers during the teaching process, appropriately select and change teaching strategies for the specific situation, by all means avoid just one in the classroom, if the students are psychologically resistant to the classroom, the teaches' teaching is equivalent to empty talk, the teaching effect must be serious dilution. Knowing a certain psychological knowledge is conducive to the control of the classroom atmosphere, it is conducive to seize the students' interest, draw the students' attention, make the best use of the situation, correctly use psychological guidance to guide the students' thinking orientation, just like Da Yu Controlling the Floods, diverting is better than blocking.

At this stage, most of the psychological counseling and tutoring organization of military colleges and local colleges exist separately, and some psychological courses and political education courses are mostly lectures, and the participation degree in the learning process of students is low, while psychological counseling institutions focus more on medical perspectives and pathological treatments, which have a certain lagging. 
If a series of psychological-oriented interventions can be adopted in the implementation ink of teaching, the role of psychology in classroom learning is deeply studied, the influence of psychological factors can be subtly integrated into the classroom, it not only can effectively alleviate negative psychological problems, but also takes positive psychology as an orientation to arouse students' learning impetus, combines psychological effects to deal with problems in the learning process, so that mental health education and professional learning can be organically combined, make the old and new contrast and complement each other, it can not only get a deep reform in the teaching operation mechanism, but also avoid taking valuable time of students outside class. However, accomplishing this goal requires hard work and unremitting efforts of teachers, it is a process that requires continuous practice and exploration, moreover, and it puts forward new requirements for the training goals and training process of the students. Using psychology stimulate learning potential is a new topic, and the development of its means requires a lot of practice and verification, in the exploration, we need to seek progress while keeping performance stable, and gradually expand.

The effective psychological stress relief form can improve the thinking and behavior habits of Non-commissioned officers to a certain extent, there are many psychological interventions that can be taken in the teaching process, for example, do questionnaire well before class, collect students' learning interests in advance, insert classic teaching cases purposefully, guide students' thinking and value orientation; organize classroom seminars, set up the questioning link, focus on solving the individual questions of the students to the greatest extent, and arouse the resonance of the students; adopt reasonable and positive incentives for the learning situation of different students, promptly affirm and encourage students with progress, build students' self-confidence and firm learning beliefs, promptly adopt classroom incentives for students left behind, let them go to the platform, blackboard to do problems, class presentations, summarize law, give appropriate hints, affirm the results in time after completion, restore confidence, and encourage fighting spirit; rationally use psychological skills, use small actions in class to reverse the negative emotions of the students, channel the students' fear of difficulty, and make the students get out of confusion; process evaluation and comprehensive consideration are used in teaching evaluation to reduce psychological pressure brought by the final exam on students, pay attention to performance in the learning process, will also make students pay more attention to the small links in learning, it is conducive to cultivation of good psychological quality and learning habits; various teaching methods are used in classroom teaching, rationally use teaching software tools, and intelligently collect students' learning condition, for example, software vote understanding or not, correctly control the teaching progress, avoid being misled by individual students, misjudge the learning progress of the entire class, cause some students to fail to keep up with learning, and feel tired of learning, etc., the introduction of similar psychological interventions will make the psychological orientation root step by step in the learning process, it will virtually bind psychological education and professional learning together, interact with each other, and get twice the result with half the effort.

For this kind of teaching method that combines psychological orientation and learning process, we can verify its effect through some methods, for example:

1). Comparative analysis of the results of the students in the pilot class and the ordinary class.

2). Research on the motivation of the students of the pilot class to answer questions and participate in seminars and other activities.

3). Analysis of the questionnaire on the mental quality of the students in the pilot class and the ordinary class.

4). Analysis of the questionnaire on the interpersonal relationship of the students in the pilot class and the general class.

Due to the particularity of Non-commissioned officers, their situation is more typical than that of local college students, military school education is an important stage in the construction of the psychological quality of the students, under the premise of adapting to the military education colleges and the military environment, the formation of a stable and healthy mental quality of students is particularly important, it not only has an important improvement to the learning effect, but also has 
an immeasurable impact on the combat capabilities of the army in the future. Therefore, it is necessary to attach importance to the psychological education of students in military schools, combine psychological quality education and professional knowledge education in the teaching process, twoway promotion, it will make the over-all quality of talents in military schools to be comprehensively cultivated.

\section{Conclusion}

In summary, relieving the psychological dilemma of Non-commissioned officers is a long and complicated project, and teachers and staff of military schools should deeply realize the significance and importance of this work. Contemporary Non-commissioned officers must not only have a deep cultural knowledge accumulation and outstanding professional ability, but also have a good psychological quality. The orientation and intervention of psychological factors can not only make the Non-commissioned officers get rid of the vicious circle caused by negative psychology, but also help the students develop healthy and good living and learning habits, therefore, it is of great significance to study the effect and guidance of psychological factors in the learning process, and it is a topic that needs to be dig deeper.

\section{References}

[1] Gao Depeng, Yao Wenshan, Chen Pinghai. Analysis of the Effect of Psychological Stress Relief Strategies of College Students [J]. Modern Communication, 2020(5): 124.

[2] Liu Xing. The Relationship between College Students' Psychological Resilience and Coping Styles[J]. Advances in Psychology, 2019(5): 436-443.

[3] Zhang Su. Research on Relationship between the Mental Elasticity of Middle School Students and Coping Styles [D]. Sichuan Normal University, 2010:16. 